\title{
Helping a Special Needs Student Learn Place Value in the Hundreds
}

\author{
Estella P. De Los Santos \\ University of Houston-Victoria, United States of America
}

\begin{abstract}
A fourth grade student's knowledge of mathematical place value was investigated. The overall goal of the work was to improve the student's understanding of place-value concepts for numbers 100 to 999. The information gained from a pre-test was used to develop an individualized education plan for the student. The concrete-semiconcrete-abstract (CSA) model was used in the sequence of lessons. This model is also known as the concreterepresentational-abstract (CRA) model. Notes were kept to monitor progress and the number of lessons at each level was determined based on the student's understanding at each level. A posttest was given after the place value lessons. There were gains in each of the three measures that were used to assess the student's knowledge of three digit place value.
\end{abstract}

\section{Introduction}

The student was in the fourth grade and this investigation was conducted during the summer after the school year. The student has been in inclusion classrooms and has gone to special education classrooms for reading, writing, and mathematics since pre-kindergarten. The student was diagnosed with mild retardation and was performing at the second grade level in the three subjects. The student was also recently been diagnosed with mild autism.

According to the student's classroom teacher, the student was having difficulty with several mathematics concepts including place value. The student had been introduced to several models in mathematics such as counters, touch points, base-ten blocks, hundreds charts, multi-link blocks and the number line. At the time of the study number charts with the 100's through the 900's had been sent home with the student. The student was not very successful in counting using the number charts. In this study the researcher addressed place-value concepts for numbers 100-999 using pictures of base ten blocks and the base ten block manipulatives.

The research objectives of the study were: 1) to assess the student's knowledge of mathematical place value for numbers 100-999, 2) to develop an individualized education plan (IEP) and 3) to use the IEP to improve the student's comprehension of place value for numbers 100 to 999 . The researcher had previously worked with this student on place value for numbers 1 to 99 [1]. At the conclusion of the 2014 study, the student was able to count, identify and show concrete and semi-concrete representations for numbers from 1 to 99 . Base ten blocks were used for the concrete, cards with base ten block pictures were used for the semi-concrete and number cards with the numbers were used for the abstract representations in the 2014 study. Since the student was successful in learning place value concepts for numbers 1-99 in the 2014 study [1], similar research review and methodology were used with adjustments in the current study to teach the student place value concepts for numbers 100-999.

\section{Literature Review}

The National Council of Teachers of Mathematics has set as one of the standards for grades Pre-K through $2^{\text {nd }}$ grade: "use multiple models to develop initial understandings of place value and the base-ten numbering system" [2]. The Common Core State Standards Initiative [3] has set understanding twodigit place value for first-grade students and threedigits for second-grade students.

\subsection{Levels of understanding place value}

In a 2007 study [4], the researchers investigated understanding of place-value concepts in 128 primary, intermediate, and junior high students. The students had mild disabilities and were grouped according to their achievement level. Six tasks were categorized for each student as being achieved at Level 1, 2, 3, or 4 with Level 4 being the highest level. For the first task the students were asked to count by tens as high as possible. The second task was to count 48 beans - ten beans in each of four cups with 8 beans on the table. For the third task the student was asked the meaning of the digits in the number 48. The fourth task was to determine conservation of grouped numbers - the researcher spilled one cup of beans on the table and asked the students if there were still the same number of beans as before. The fifth task was knowledge of the relationship between the digits and a collection of ungrouped numbers - the student was asked to count 25 tongue depressors and then asked questions about the correspondence of the counters with the number 25. The sixth task was to determine if the student 
understood that the position of digits determines the value of the number. The results showed that a higher percentage of the students in the junior high group attained Level 4 for each of the six tasks. They were followed by the intermediate group and the least number coming from the primary group. Cawley et. al. [4] found that student performance increased with age which indicated a developmental trend. The results were similar to those of Ross [5], who found that higher performance correlated with age and grade level.

Learning place value concepts involves synthesizing four mathematical properties [6]: 1) Positional property - the quantity represented by an individual digit in a numeral is determined by the position of the digit in the numeral. For example, the digit 3 represents a different quantity in the number 333 , depending on the position in the numeral. 2) Base-ten property - the place values of the positions increase by powers of ten from right to left. For the number 234, we use the hundred's place, ten's place, and one's place. 3) Multiplicative property-the value of an individual digit is determined by multiplying the value of the digit by the place value assigned to the position of the digit. For example, in the number 453, the value of the digit 5 is determined by multiplying 5 times 10 ; so the value of the digit 5 is fifty. 4) Additive property-the quantity represented by the entire numeral is the sum of the values represented by the individual digits. For example, the value of the number 453 is 4 times 100 plus 5 times 10 plus 3 times 1 or $4 \times 100+5 \times 10+$ $3 \mathrm{x} 1$ which is 453 .

A student who understands place value properties, understands that in the numeral 234 , the ' 2 ' ' is in the hundreds position, the ' 3 ' is in the tens position, and the ' 4 ' is in the ones position. Additionally, the student knows that the ' 2 ' represents two hundreds, the ' 3 ' represents three tens and the ' 4 ' represents four ones. Also, the student knows that the value of the ' 2 ' is two hundred, the value of the ' 3 ' is thirty, and the value of the ' 4 ' is four. Cumulatively, the student understands that the value of the numeral is $200+30+4$ or 234 [6].

Susan Ross [5], [6], [7] investigated two-digit place value concepts with second through fifth grade students. She proposed five stages in the development of children's understanding of place value. For the current study, the definitions have been adapted for three digit numerals. In the first stage, the child is able to read and write three-digit numerals and associate them with the number of objects that they represents; however the child does not know the meaning of the three digits. In the second stage, the child knows that the digit on the right is in the "ones place" the digit in the middle is in the "tens place" and the digit on the left is in the "hundreds place"; however the child does not understand the quantity represented by each digit. In the third stage, the child can state that the digit on the left represents " $x$ " number of "hundreds", the digit on the right represents " $y$ " number of "tens", and the digit on the right represents " $z$ " number of "ones"; but does not know that the objects represented by the ones, tens, and hundreds are different objects. In stage four, the child knows that the digit on the left represents sets of hundred objects, the digit in the middle represents sets of ten objects, and the digit on the right represents single objects; however this knowledge is not consistent when presented with non-canonical partitioning of objects. In stage four and five, the children understand part-whole relationships. Stage five differs from stage four in that "the quantity of objects corresponding to each digit can be determined even for collections which have been non-canonically partitioned" [7].

Canonical partitioning is the traditional representation. For example, 25 is represented with two "tens" and five "ones". Non-canonical partitioning would be an alternate representation which, for a three digit numeral, may include using more than nine "tens" or more than nine "ones". A non-canonical partitioning for 25 would be one "ten" and fifteen "ones" [7].

The canonical partitioning for 357 would be three "hundreds, five "tens", and seven "ones". A noncanonical partitioning for 357 may be two "hundreds", fifteen "tens" and seven "ones" or three "hundreds", four "tens" and seventeen "ones". These non-canonical partitioning skills are necessary for understanding renaming concepts in addition and subtraction problems. For example, a sum that results in seventeen "ones" is renamed to one "ten" and seven "ones". In subtraction, 357 will need to be renamed to three "hundreds", four "tens" and seventeen "ones", in order to subtract nine "ones".

Part-Whole relationships can be taught to young children, for example by asking them to count 10 objects. Then divide the objects into two groups such as a group of two and eight, three and seven, four and six or five and five. Next ask them to count the objects again [8]. At first children do not see a pattern in numbers between 10 and 20. They see these as nine additional numbers and words. It is important to use activities were the students can identify fifteen as ten and five more [8]. The use of base ten blocks enhances students' understanding of place value.

\subsection{Helping students with disabilities}

Miller and Hudson [9] provided several guidelines for helping students with disabilities understand math concepts: use several models to represent the concepts, use appropriate lesson structures for specific concepts, use appropriate mathematical language, use real life applications, and use clear and explicit instruction. 
Fuchs et.al. [10] discus seven principles of effective instruction that may be used for students with mathematical disabilities: "instructional explicitness, instructional design to minimize the learning challenge, strong conceptual basis, drill and practice, cumulative review, motivators to help students regulate their attention and behavior to work hard, and ongoing progress monitoring" [10]. These principles were interwoven into the current case study.

In the current study, hands-on manipulatives in the form of the base ten blocks were used to teach the student place value concepts, which are quite abstract concepts. The picture cards of the base ten blocks were used to connect the concrete models with the abstract models or numerals. The lessons were structured so that the concrete lessons came first, the semi-concrete lessons were second and the abstract or numerical representations came last. The number of lessons depended on the understanding that the student had before progressing to the next stage. Appropriate mathematical language and questioning was used in order to assess the student's progress during the lessons.

These strategies are important not only for students with mathematical disabilities; but for all students to gain a conceptual understanding of mathematics.

\subsection{Concrete-semiconcrete-abstract model}

The concrete-semiconcrete-abstract (CSA) model utilizes a natural progression of lessons at each of the three levels. At the concrete stage, students are taught with 3 dimension models such as the base-ten blocks. At the semi-concrete stage, students use two dimension drawings to solve the problems such as pictures, tallies, diagrams or drawings of the base-ten blocks. In the last stage, the abstract stage, students work with numbers only and do not use manipulatives or drawings. The CSA model is also referred to as the Concrete-representational-abstract or CRA model [11], [12], [13], [14].

The concrete-representational-abstract (CRA) sequence of instruction has also been combined with the Strategic Instruction Model (SIM), which is explicit instruction with emphasis on procedural knowledge. The CRA-SIM has been found to be effective in teaching computation skills to students with learning disabilities or at risk students [15], [16], [17].

Miller, Mercer, and Dillon [18] recommend that a minimum of nine instruction lessons: three at the concrete phase, three at the semiconcrete phase, and three at the abstract phase, be provided when using the CSA or CRA model. They also recommend that four steps be included in each lesson: provide an advanced organizer, demonstrate and ask students to model the skill, provide guided practice with feedback, and provide the student with independent practice. The researcher used these four steps in designing the place value lessons for the student in the current case study. Extra lessons were designed in case the student needed more than the recommended three lessons at each phase of the instructional model.

Mercer and Miller [19] used ten lessons. The concrete manipulatives were used in Lessons 1-3, the representational phase was used in Lessons 4-6. Lesson 7 was and introduction of math strategies to help students make the transition into the last phase. This extra transition lesson is an addition to the nine lessons proposed by Miller, Mercer, and Dillon [18. Lessons 8-10 were at the abstract phase. The ten lessons were preceded with a pretest and followed by a posttest.

Place value is a complex concept for young children to grasp [20] and develops over time [21]. It is very important to teach place value concepts to elementary aged children using the concreterepresentational-abstract (CRA) or concretesemiconcrete-abstract (CRS) model. Ross [6] found that 20 percent of grade 2 students and 33 percent of grade 3 students that she tested were successful in showing that the ' 2 ' in ' 25 ' represented twenty sticks and it was not until grade 4 that the percentage exceeded 50 percent. Kami and Joseph [22] found similar results when they interviewed students' understanding that the ' 1 ' in ' 16 ' meant ten. They found that 0 percent of grade 1 students, 33 percent of grade 3 students, and 50 percent of grade 4 students were successful. Teaching place value with an emphasis in understanding rather than only using symbolic representation has a much more positive effect and helps students be successful with learning future mathematical concepts [23], [24].

\section{Methodology}

The case study served to (a) identify the unique needs of the student, (b) guide the selection of instructional content and materials, (c) create an individualized education plan (IEP), (d) monitor student progress, and (e) evaluate learning. [25] Adequate representation of content, appropriate scope and sequence of the content and developmentally appropriate content were addressed to insure accurate measures.

The author developed two questionnaires, Form A and Form B, modeled after the work of Susan Ross [5], [6], [7]. Form A was used as a diagnostic pretest and Form B was used as a summative evaluation or posttest of the individualized instruction. The assessments were used to determine if the student had comprehension of place-value concepts for numbers 100 to 999.

Based on the results of the diagnostic assessment, the researcher developed an IEP to extend the 
student's understanding of place value. Formative evaluations were included in the IEP. The instructional methods and materials were developmentally appropriate for the student. The instructional sequence followed the CSA or CRA models [11], [12], [13], [14]. Each instructional session was approximately 20 minutes in length. The instructional timeline was individualized and adjusted according to the student's needs.

\subsection{Subject}

The student was in the fourth grade and this investigation was conducted during the summer after the school year. The student has been in inclusion classrooms and has gone to special education classrooms for reading, writing, and mathematics since pre-kindergarten. The student was diagnosed with mild retardation and was performing at the second grade level in the three subjects. The student was recently diagnosed with mild autism.

\subsection{Materials}

Base-ten blocks and place value chart were used in the first phase - the concrete stage. The smallest block represents the unit or the number one. Ten unit blocks connected together are referred to as the "Ten Stick", "Rod" and are the representation for the number ten. Ten "Ten Sticks" connected together are referred to as the "hundred square", "Flat" and are the representation for the number one-hundred. See Figure 1.

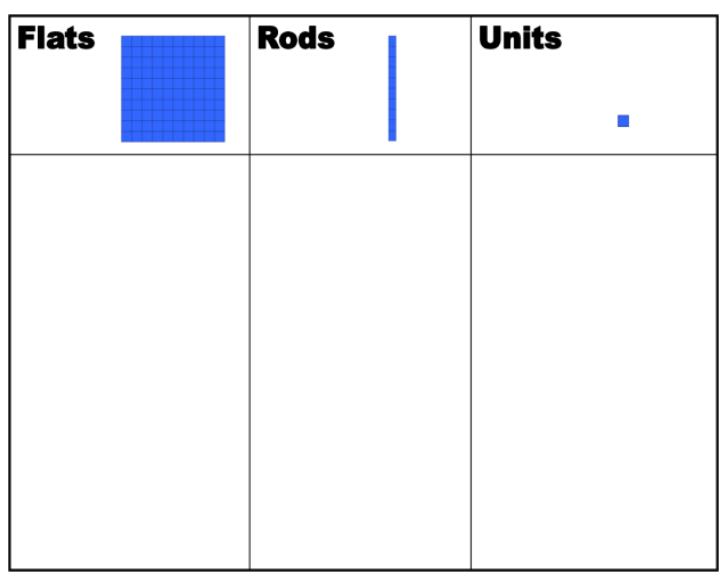

Figure 1. Place value chart

Number cards with illustrations of the base-ten block representation for the number were used in the second phase - the semi-concrete stage. The number cards were created by the researcher, printed with six numbers and illustrations per page, and collected in a binder with page protectors for the student to use.

The card illustrated in Figure 2 represents an example of a number card used in the current study.
The number card had the number printed at the top with the illustration of the number with base ten blocks below the number. In the example, the number " 324 " is printed at the top of the card with three" hundreds", two "tens", and four "ones" in the illustration below the number. See Figure 2.

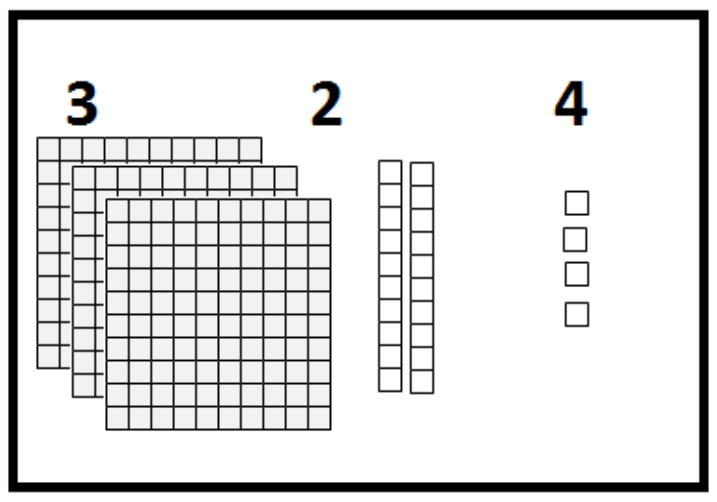

Figure 2. Number cards with base-ten block representation for number

Hundred charts were used in the third phase - the abstract stage. There were nine hundred-charts. One chart was for the one hundreds, a second chart for the two hundreds, and on to the ninth chart for the nine hundreds. The hundred chart for the five hundreds is illustrated in Figure 3. The hundred chart contains numerals five hundred one to six hundred.

\begin{tabular}{|l|l|l|l|l|l|l|l|l|l|}
\hline 501 & 502 & 503 & 504 & 505 & 506 & 507 & 508 & 509 & 510 \\
\hline 511 & 512 & 513 & 514 & 515 & 516 & 517 & 518 & 519 & 520 \\
\hline 521 & 522 & 523 & 524 & 525 & 526 & 527 & 528 & 529 & 530 \\
\hline 531 & 532 & 533 & 534 & 535 & 536 & 537 & 538 & 539 & 540 \\
\hline 541 & 542 & 543 & 544 & 545 & 546 & 547 & 548 & 549 & 550 \\
\hline 551 & 552 & 553 & 554 & 555 & 556 & 557 & 558 & 559 & 560 \\
\hline 561 & 562 & 563 & 564 & 565 & 566 & 567 & 568 & 569 & 570 \\
\hline 571 & 572 & 573 & 574 & 575 & 576 & 577 & 578 & 579 & 580 \\
\hline 581 & 582 & 583 & 584 & 585 & 586 & 587 & 588 & 589 & 590 \\
\hline 591 & 592 & 593 & 594 & 595 & 596 & 597 & 598 & 599 & 600 \\
\hline
\end{tabular}

Figure 3. Hundred Chart

\section{Results}

The researcher used a pretest to assess the student's level of understanding of mathematical place value for numbers 100-999. An individualized education plan (IEP) was developed and administered according to the results of the pretest. The IEP included formative evaluation allowing for adjustments in place value instruction during the process. A posttest was administered to determine student progress after the instruction. The results of the posttest will be provided to the student's 
classroom teacher in order that the student's needs may be more adequately addressed.

\subsection{Pretest}

The hundred charts and number cards with illustrations were used for the pretest. The hundred charts were used in the student's fourth grade classroom. 1) The student was asked to state the name of numbers that the researcher pointed to on the hundred charts. 2) The student was asked to find and state the meaning of the digits of numbers selected on the number cards. 3) The student was given a number orally by the researcher and asked to find the number on the hundred charts.

The results of the pretest showed: 1) The student was able to state the name of numbers selected on the hundred chart with 80 percent accuracy. 2) The student could find and state the name and meaning of selected numbers on the number cards with 80 percent accuracy. 3) When given a number orally, the student had difficulty finding the number on the hundred charts. The student showed frustration at this task and did not want to finish this part of the assessment; so finished with 30 percent accuracy.

It was determined that the student was at the third of five stages in the development of children's understanding of three-digit place value according to Susan Ross [5], [6], [7]. In the third stage, the student can state that the digit on the left represents " $x$ " number of hundreds, the digit in the middle represents " $y$ " number of tens, and the digit on the right represents " $z$ " number of ones. However, the student did not know how the objects are different. This evaluation was made because the student wasn't consistent in differentiating between three-digit numbers that ended with 12 and 20, 13 and 30, 14 and 40, 15 and 50, 16 and 60, 17 and 70, 18 and 80, and 19 and 90. It may because of the similar sounding names such as twelve and twenty, thirteen and thirty, fourteen and forty, fifteen and fifty, sixteen and sixty, seventeen and seventy, eighteen and eighty, and nineteen and ninety.

\subsection{Individualized education plan (IEP)}

The instruction was divided into three parts: the concrete, semi-concrete, and abstract phases. The base-ten blocks and place value chart were used with concrete instruction, the number cards were used with semi-concrete instruction, and the hundred charts were used with abstract instruction.

There were seven lessons using the concrete manipulatives. During the first two lessons the researcher said a number orally, placed number cards without pictures in the correct column on the place value chart, and the student was able to place the correct representation for each of the numbers using the base-ten block manipulatives. The researcher stated the numbers orally beginning with the third lesson, since the student had difficulty with this task during the pretest. The student was able to place the correct cards and show the correct base-ten block representation for most of the numbers. The student had difficulty with numbers such as 305 . Initially, the student placed the number cards and base-ten blocks for " 350 " on the place value chart instead of the representations for " 305 ". In order to clarify the difference, the researcher showed the student the number cards with illustrations for " 350 " and " 305 ". Questions were asked by the researcher to make sure that the student understood the difference between the two numbers. The student was able to identify both numbers in the illustrations and then provided the correct representations on the place value chart with the base-ten blocks. See the student's final answer in Photo 1.

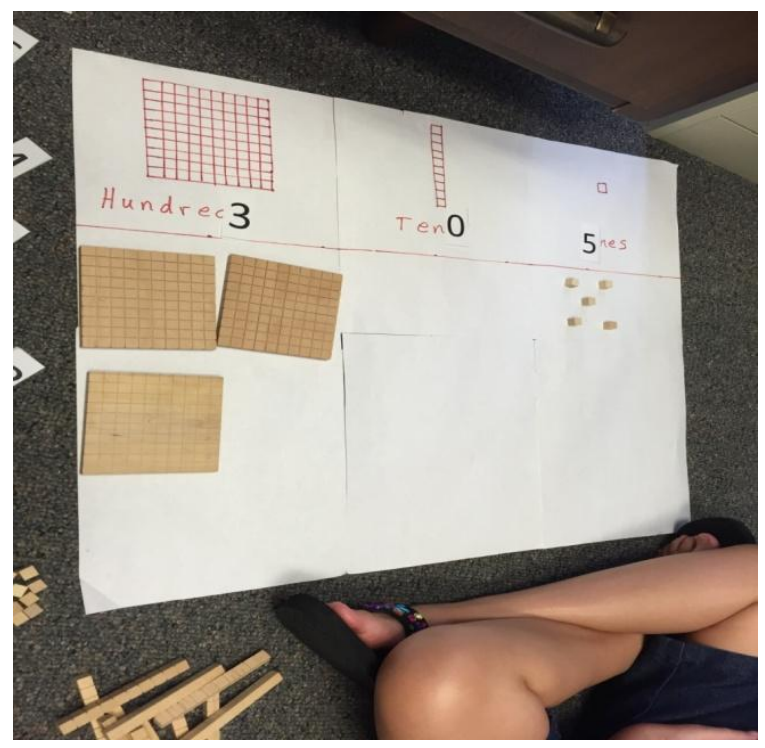

Photo 1. Representation for "305" on Place Value Chart

The student also had difficulty with numbers such as " 550 " versus " 515 " and " 215 " versus " 250 ". This problem, for example differentiating between fifteen and fifty, was noticed in the pretest; so many of these types of numbers were used at this stage of the instructional sequence. The researcher showed many examples, allowed for guided practice, asked questions to check for understanding, and gave the student many opportunities to work the problems independently. For " 215 " versus " 250 ", the student was able to find the number cards with illustrations for both " 215 " and " 250 " in the binder, then was able to provide the correct number cards and base-ten block representations on the place value chart (see Photo 2). 


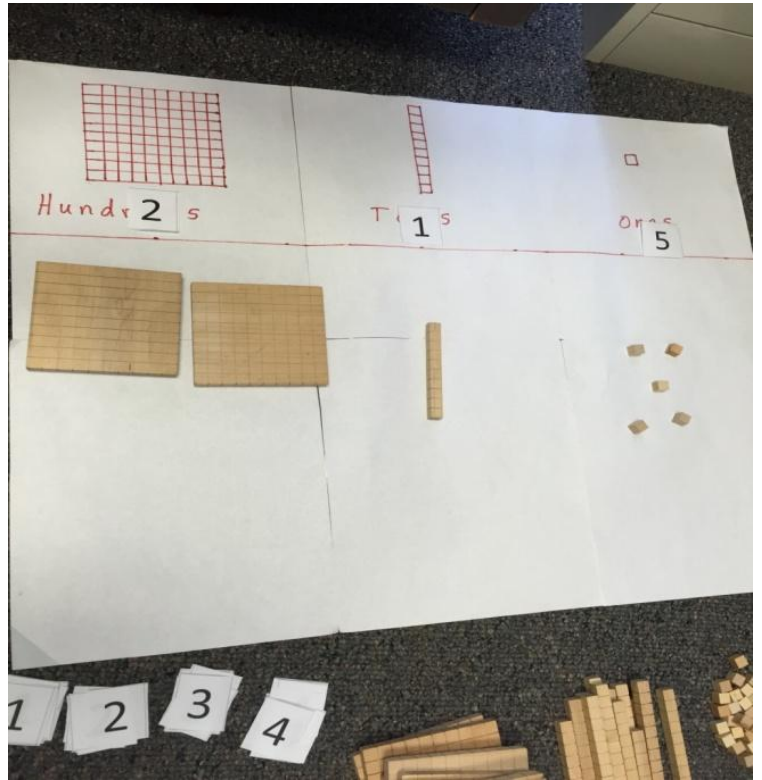

Photo 2. Representation for " 215 " On the Place Value Chart

At one point the student showed frustration with the lessons. Most of the time, the student brought a stuffed animal with her to the instructional sessions. The researcher told the student that she could let the stuffed animal be included in the pictures. This was motivational for the student and she was able to continue with the lessons. See Photo 3.

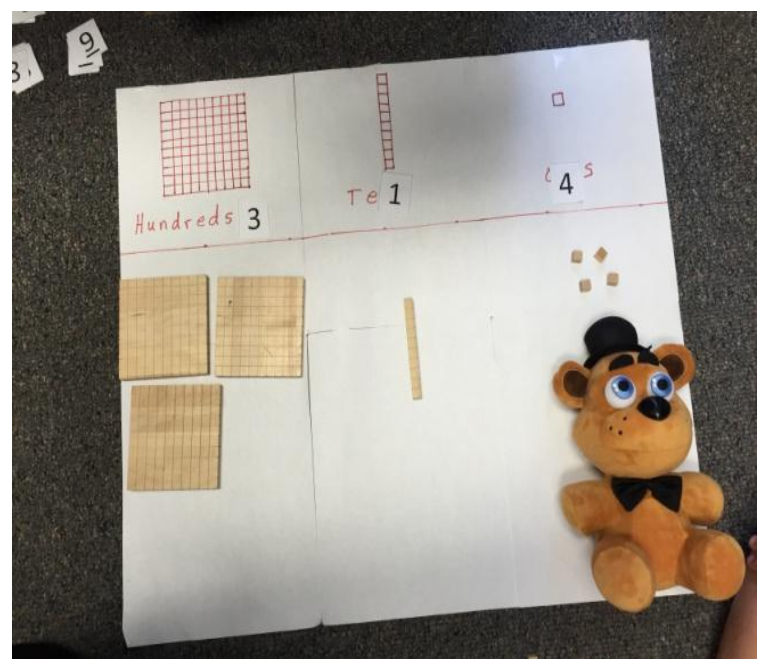

Photo 3. Representation for "314" On the Place Value Chart

There were four lessons using the semi-concrete manipulates. During this phase the number cards with illustrations were used. The student was given a number orally and was then asked to find the number card in the binder. The student was able to locate numbers and tell how many hundreds, tens, and ones were contained in the given number. Other questions were asked such as: 1) "Which number is bigger?" Here the student was asked to find the two numbers in the binder and state which one was the larger or smaller number. 2) "What is the smallest or largest number on these two pages?", 3) "What is the number, if you add one more to the given number?", 4) "What does the 4 mean in 341?", 5) Which digit in the number 341 represents the most or least number of blocks?", etc.

The student had difficulty finding " 318 " versus " 380 " and "515" versus " $550 "$ "; so more time was dedicated to numbers in the hundreds ending with 11-19. This was the same problem that the student had shown throughout the pretest and concrete phase of the lessons. The instructor would point to a number card and the student would identify the number (see Photo 4).

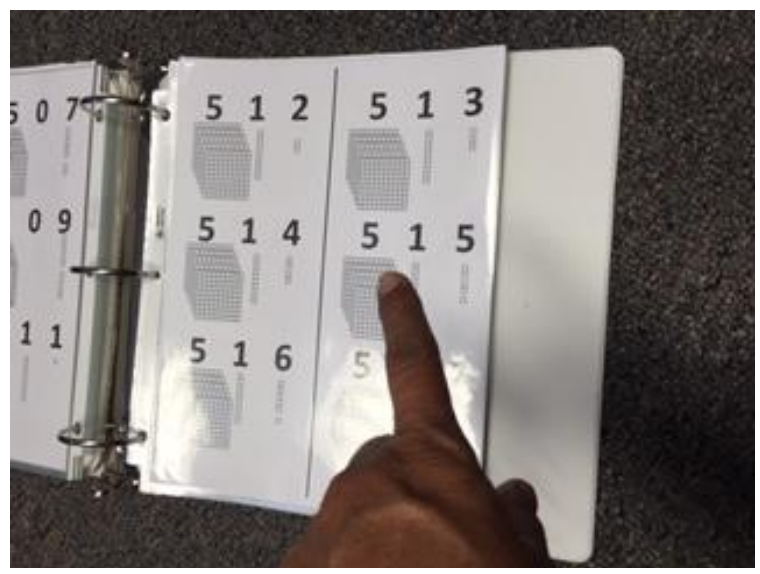

Photo 4. Finding " 515 " on the Number Cards with Base-Ten Block Illustrations

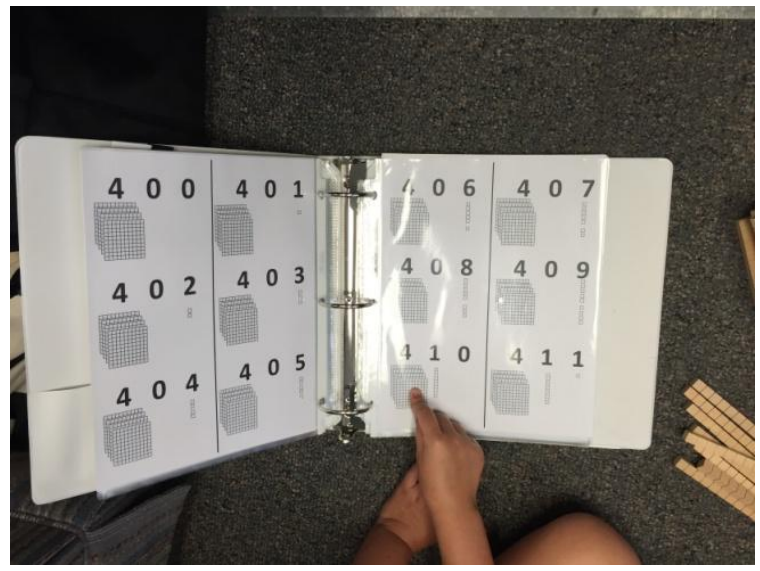

Photo 5. Finding "410" on the Number Cards with Base-Ten Block Illustrations

Since the student also had difficulty with numbers containing a zero, time was also dedicated to these types of problems. Questions were asked to check for understanding. The researcher would also state a number orally and the student would find the number card (see Photo 5). 
The last two lessons were in the abstract stage. The nine hundred-charts were used for these lessons. The researcher would state a number such as " 680 " and the student would find the number in one of the hundred charts that were in the binder. The student is pointing to the correct numeral in Photo 6 . Questions similar to those asked during the lessons in the second phase were also asked during the third phase (see Photo 6).

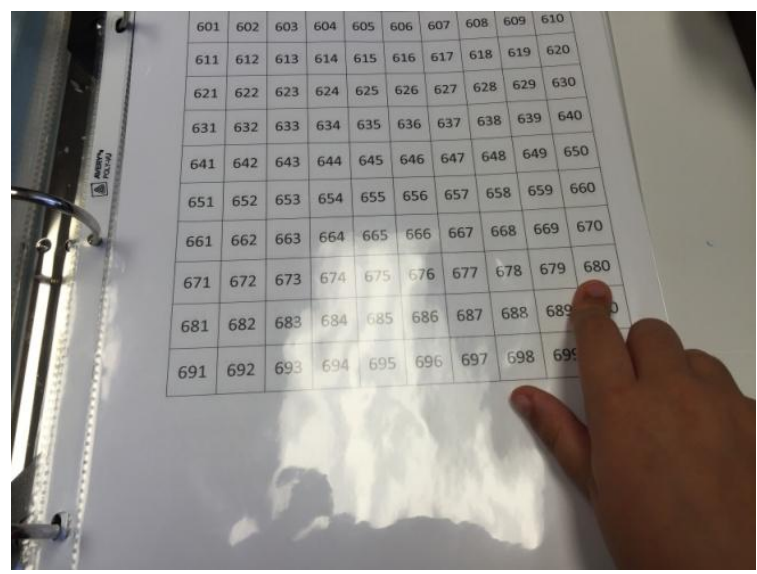

\section{Photo 6. Finding "680" on Hundred Charts}

Another task using the hundred charts was for the researcher to point to a number and have the student identify the number. The researcher is pointing to the number " 250 " in Photo 7 and then asked the student to identify the number. See Photo 7.

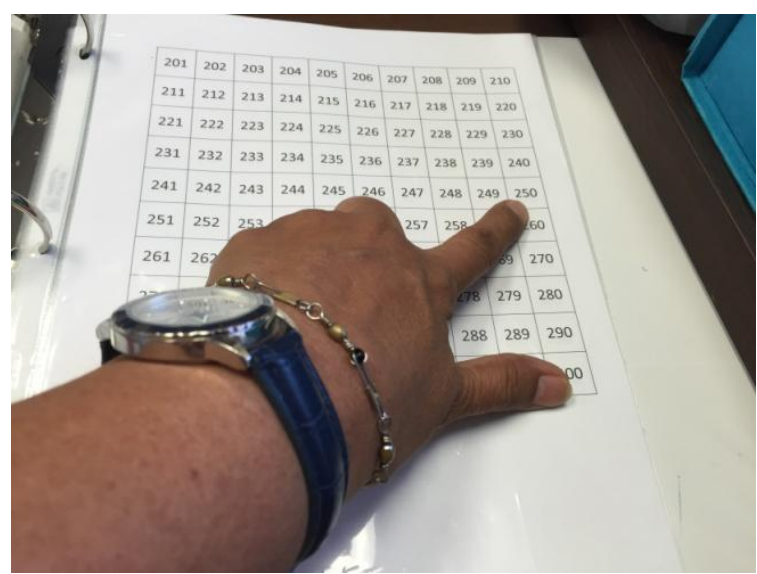

Photo 7. Identifying "250” on Hundred Charts

\subsection{Posttest}

The results of the posttest showed: 1) The student could state the name of numbers selected on a hundred chart with 90 percent accuracy. This was a 12.5 percent increase from the pretest score of 80 percent. 2) The student could find and state the name and meaning of selected numbers on the number cards with 100 percent accuracy. This was a 25 percent increase from the pretest score of 80 percent. 3) When given a number orally, the student could find the number on the hundred charts with 100 percent accuracy. This was a 233 percent increase from the pretest score of 30 percent, where the student became frustrated and refused to try to locate some of the numbers on the hundred charts (see Table 1).

Table 1. Pretest and posttest results

\begin{tabular}{|l|l|l|l|}
\hline $\begin{array}{l}\text { Place } \\
\text { Value Skill }\end{array}$ & Pretest & Posttest & $\begin{array}{l}\text { Percent } \\
\text { Increase }\end{array}$ \\
\hline $\begin{array}{l}\text { State } \\
\text { name of } \\
\text { numbers } \\
\text { selected } \\
\text { on } \\
\text { hundred } \\
\text { chart }\end{array}$ & $80 \%$ & $90 \%$ & $12.5 \%$ \\
\hline $\begin{array}{l}\text { Find and } \\
\text { state name } \\
\text { and } \\
\text { meaning of } \\
\text { selected } \\
\text { numbers } \\
\text { on number } \\
\text { cards }\end{array}$ & $80 \%$ & $100 \%$ & $25 \%$ \\
\hline $\begin{array}{l}\text { Given a } \\
\text { number } \\
\text { orally, find } \\
\text { number on } \\
\text { hundred } \\
\text { charts }\end{array}$ & $30 \%$ & $100 \%$ & $233 \%$ \\
\hline
\end{tabular}

\section{Conclusions}

The student finished the fourth grade and will be in the fifth grade during the next school year. The student is at least two grade levels below grade level in mathematics. The researcher has previously worked with this student on mathematical place value and addition of two digit whole numbers. The student has mastered two digit numbers and three digit place value. After this study the researcher will work with the student on three digit addition.

At the beginning of the study, it was determined that the student was at the third of five stages in the development of children's understanding of place value according to Susan Ross [5], [6], [7]. At the conclusion of the current study it was determined that the student has an understanding of hundreds place value at Stage Four. The child knows that the digit on the left represents sets of hundred objects, the digit in the middle represents sets of ten objects and that the digit on the right represents single objects. In order for the child to have understanding of place value at Stage Five, the knowledge has to be 
consistent when presented with non-canonical partitioning of objects. This task will be addressed when the student adds three digit numbers and uses renaming and regrouping skills. The student will then need to understand that numbers such as " 120 " may be represented as one "hundred" plus two "tens" or as twelve "tens".

The student has made significant progress in the three years that the researcher has worked with her on two digit place value, two digit addition, and three digit place value. Many students do not receive instruction using base-ten blocks or other manipulatives; so they do not have a thorough understanding of place value. Many students are able to give a correct verbal response such as the 2 in the number " 25 " represents two "tens"; however, many do not understand the place value concepts. Many would say that the 5 in the number " 25 " represents more blocks than the 2 in " 25 ". The researcher believes that this student in this case study is building a stronger mathematical foundation by using developmentally appropriate materials, research-based lesson design and lesson sequence. The researcher hopes to continue working with this student so she may master mathematical concepts at her pace.

\section{References}

[1] De Los Santos, E. and B. Patton, "Making Mathematical Place Value Meaningful for a Special Needs Student", International Journal of Technology and Inclusive Education, Vol. 1 No. 2, 2014, pp. 455-458.

[2] National Council of Teachers of Mathematics, Principles and Standards for School Mathematics, NCTM, Reston, Va, 2000, p. 78.

[3] Common Core State Standards Initiative, Preparing America's Students for College \& Career, Mathematics Standards, 2014, Grade 1 \& Grade 2.

[4] Cawley, J.F., R.S. Parmar, L. Lucas-Fusco, J.D. Kilian, and T.E. Foley, "Place value and mathematics for students with mild disabilities: Data and suggested practices", Learning Disabilities: A Contemporary Journal, Vol. 5 No. 1, 2007, pp. 21-39.

[5] Ross, S. The Development of Children's Place-Value Numeration Concepts in Grades Two through Five, 1986, Paper presented at the annual meeting of the American Educational Research Association, San Francisco, CA.

[6] Ross, S. "Parts, wholes and place-value: A developmental view", Arithmetic Teacher, Vol. 36 No. 6, 1989, pp. 47-51.

[7] Ross, S. "Children's acquisition of place-value numeration concepts: The roles of cognitive development and instruction", Focus on Learning Problems in Mathematics, Vol. 12 No. 1, 1990, pp. 1-17.
[8] Van De Walle, J.A., K.S. Karp, and J.M. BayWilliams, Elementary and Middle School Mathematics: Teaching Developmentally, Allyn \& Bacon, Boston, MA, 2010.

[9] Miller, S.P. and P.J. Hudson, "Helping Students with Disabilities Understand What Mathematics Means", Teaching Exceptional Children, Vol. 39 No. 1, 2006, pp. 28-35.

[10] Fuchs, L.S., D. Fuchs, S.R. Powell, P.M. Seethaler, P.T. Cirino, and J.M. Fletcher, "Intensive Intervention for students with mathematics disabilities: Seven Principles of Effective Practice", Learning Disability Quarterly, Vol. 31, Spring 2008, pp. 79-92.

[11] Miller, S.P., J.L. Stringfellow, B.J. Kaffar, D. Ferreira, and D.B. Manel, "Developing Computation Competence Among Students Who Struggle with Mathematics", Teaching Exceptional Children, Vol. 44 No. 2, Nov. 2011, pp. 38-46.

[12] Manel, D.B., S.P. Miller, and M. Kennedy, "Using the Concrete-Representational-Abstract Sequence with Integrated Strategy Instruction to Teach Subtraction with Regrouping to Students with Learning Disabilities", Learning Disabilities Research \& Practice, Vol. 27 No. 4, 2012, pp. 152-166.

[13] Mudaly, V. and J. Naidoo, "The concreterepresentational-abstract Sequence of Instruction in Mathematics Classrooms", Perspectives in Education, Vol. 33 No. 1, 2015, pp. 42-56.

[14] Stroizer, S., V. Hinton, M. Flores, and L. Terry, "An Investigation of the Effects of CRA Instruction and Students with Autism Spectrum Disorder", Education and Training in Autism and Developmental Disabilities, Vol. 50 No. 2, 2015, pp. 223-236.

[15] Flores, M.M., V.M. Hinton, S.D. Strozier, and S.L. Terry, "Using the Concrete-representational-abstract Sequence and the Strategic Instruction Model to Teach Computation to Students with Autism Spectrum Disorders and Developmental Disabilities", Education and Training in Autism and Developmental Disabilities, Vol. 49 No. 4, 2014, pp. 547-554.

[16] Hinton, V., S.D. Strozier, and M.M. Flores, "Building Mathematical Fluency for Students with Disabilities or Students At-Risk for Mathematics Failure", International Journal of Education in Mathematics, Science and Technology, Vol. 2 No. 4, Oct. 2014, pp. 257-265.

[17] Flores, M.M., Hinon, V.M., and K.B. Schweck, "Teaching Multiplication with Regrouping to Students with Learning Disabilities", Learning Disabilities Research \& Practice, Vol. 29 No. 4, 2014, 171-183.

[18] Miller, S.P., C.D. Mercer, and A.S. Dillon, "CSA: Acquiring and Retaining Math Skills", Intervention in School and Clinic, Vol. 28 No. 2, Nov. 1992, pp. 105-110.

[19] Mercer, C.D. and S.P. Miller, "Teaching students with learning problems in math to acquire, understand, and 
apply basic math facts", Remedial and Special Education, Vol. 13, 1992, pp. 19-35.

[20] Kami, C., "Place value: An explanation of its difficulty and implications for the primary grades", Journal for Research in Childhood Education, Vol. 1 No. 2, 1986, pp. 75-86.

[21] Thomas, N. and J. Mulligan, "Children's Understanding of the Number System", Mathematics Education Research Group of Australia, Vol. 22, 1999, pp. 477-484.

[22] Kami, C. and L. Joseph, "Teaching place value and double-column addition", Arithmetic Teacher, Vol. 35 No. 6, 1988, pp. 48-52.

[23] Hiebert, J. and D. Wearne, "Links between Teaching and Learning Place Value with Understanding in First Grade", Journal for Research in Mathematics Education, Vol. 23 No. 2, 1992, pp. 98-122.

[24] Wearne, D. and J. Hiebert, "Research into Practice: Place value and Addition and Subtraction", Arithmetic Teacher, Vol. 41 No. 5, 1994, pp. 272-274.

[25] Parmar, R.S., R. Frazita, and J.F. Cawley, "Mathematics Assessment for Students with Mild Disabilities: An Exploration of Content Validity", Learning Disability Quarterly, Vol. 19, Spring 1996, pp. 127-136. 